\title{
O tempo da paisagem e o tempo da ciranda: breve reflexão sobre o tempo nas narrativas Paisagem sem barcos, de Maria Judite Carvalho e Ciranda de pedra, de Lygia Fagundes Telles
}

Geruza Zelnys de Almeida ${ }^{1}$

RESUMO: O artigo aproxima as narrativas Paisagem sem barcos, da escritora portuguesa Maria Judite de Carvalho, e Ciranda de pedra, da escritora brasileira Lygia Fagundes Telles analisando a construção do tempo e da memória em textos de autoria feminina no Brasil e em Portugal.

ABSTRACT: The article compares two narratives: Paisagem sem barcos, written by Portuguese author Maria Judite de Carvalho and Ciranda de pedra, written by Brazilian author Clarice Lispector. This text shows the construction of the time and the memory in texts written by women in Brazil and Portugal.

PALAVRAS-CHAVE: Narrativa; Literatura Comparada; Tempo; Memória; Literatura Feminina

KEYWORDS: Narrative; Comparison; Time; Memory; Feminine Literature

A disposição cronológica na novela Paisagem sem barcos, de Maria Judite de Carvalho, e no romance Ciranda de pedra, de Lygia Fagundes Telles, revela o fio estrutural que alicerça projetos autorais amparados na mobilidade do tempo. Nestas narrativas, o tempo constrói-se num vai-e-vem memorialístico que une presente e passado englobando circularmente personagens e acontecimentos. Consequentemente, o elemento temporal funciona como agente de dinamismo e simultaneidade na vida das protagonistas, as quais são marcadas por uma forte vivência interior que as distingue das demais personagens aparentemente fúteis, frias ou apáticas.

No estudo dessas narrativas, observa-se que o fator temporal determina o aparecimento de duas temporalidades distintas inscritas

1 Doutoranda em Teoria Literária e Literatura Comparada pela USP. Contato: zelnys@hotmail.com 
na imanência das obras: em Paisagem sem barcos constrói-se o tempo da paisagem e, em Ciranda de pedra, o tempo da ciranda. Esses dois modos de presentificação do tempo interferem na construção das personagens transformando estaticidade e completude, respectivamente, em movimento dialógico e incompletude.

O presente artigo analisa as protagonistas a partir da relação que mantêm com o tempo e com as imagens a ele ligadas, já que para Bakhtin (1998) o tempo está intrinsecamente ligado ao espaço e pode ser condensado em imagens especificas portadoras de grande significação dentro da narrativa. Essa imagem espácio-temporal é chamada pelo teórico de cronotopo, ou seja, o elemento textual onde os “nós do enredo são feitos e desfeitos” (1998, p. 355).

Seguindo a concepção bakhtiniana, os cronotopos se associam à "grande temporalidade", isto é, à simultaneidade com a qual somos "inclinados a reconstruir a atualidade (o presente) segundo uma linha vertical que sobe e desce" (Idem, p. 264). Ou seja, o tempo é por princípio composto: o presente é feito do passado e está preparando-se para uma transformação no futuro, por isso não é estático e sim movente e processual.

Distinguir esses cronotopos é possivel observando que eles são representados artisticamente através de imagens que condensam a fusão tempo-espaço. Essas imagens se apresentam com certa recorrência e detêm as linhas construtivas das narrativas, por isso importa-nos persegui-las para verificar como elas determinam o caráter das protagonistas.

\section{O tempo à deriva na Paisagem sem barcos, de Maria Judite de Carvalho}

Em Paisagem sem barcos, o presente convive com um passado "paisagístico" observado através de uma janela virtual aberta no 
discurso pela protagonista. Assim, o leitor é convidado a conhecer fatos, pessoas e acontecimentos importantes na vida de Jô e seus reflexos no presente da narração. Nota-se, porém, que tanto passado quanto presente são variações da mesma paisagem recortada para a observação do leitor que, com a ajuda das continuas anacronias discursivas, percebe a simultaneidade própria do tempo psicológico ou das narrativas de "tensão interiorizada".

A escritora portuguesa conseguiu materializar o vai-e-vem de um tempo que, como ondas no mar, desliza entre presente e passado dando à narrativa um caráter cíclico ou periódico, no qual coisas e pessoas se repetem e nada de fato parece se transformar na vida da protagonista Joana, mulher dividida entre o relacionamento insípido com o namorado atual e a aparição repentina e passageira de um antigo amor.

Voltando incessantemente sobre si mesmo, o tempo já se indicia no primeiro parágrafo, na repetida confissão parentética "(mais uma vez)" que aponta os desdobramentos ocorridos ao longo da novela. Isso pode ser verificado, por exemplo, nos dois sedativos, na amiga Paula refletida na mãe de Joana, na diretora que repete a intervenção dos pais na sua vida amorosa, entre outros casos que se tornam episódicos.

A memória temporal da protagonista é ativada logo no início da narrativa pela personagem Paula que, à distância, conversa pelo telefone com Joana. Espécie de elo temporal, Paula - mais especificamente sua "voz" - liga Joana à infância e adolescência, pois sempre estivera presente representando, de certa forma, a permanência e a imutabilidade das coisas. Paula tem ainda a função de espelho pelo qual Joana dá-se a conhecer, já que em nenhum momento é caracterizada explicitamente; apenas em nada se parece à amiga, sendo, portanto, oposta à imagem produzida de Paula.

O interesse de Joana pela voz das pessoas parece estar ligado ao desejo mágico pela palavra proferida que pode voltar em eco dos confins da memória. Isso porque, segundo Zumthor (1997, p, 97), a voz "estabelece ou restabelece uma relação de alteridade, que funda a 
palavra do sujeito", ou seja, a voz atravessa a "clausura do corpo" possibilitando que ele não se reduza ao lugar em que se encontra.

Sendo assim, o telefone na narrativa configura-se como uma imagem cronotópica, na qual tempo e espaço interligam-se: é por meio do aparelho telefônico que os destinos se cruzam e o presente e passado comprimem-se. Talvez por isso, o desligar do aparelho é chamado de "corte brusco", ou seja, o tempo-espaço das lembranças é cortado para dar lugar ao presente, ou ainda, ao "beco sem saída que era sua existência, e onde se encontrava com problemas, sem projetos e sem esperanças" (p. 14).

Diferentemente do telefone, que possui uma carga positiva, o relógio é uma imagem insistente que a acompanha no tempo presente e que a chama "brutalmente" à vida. O presente de Joana é Artur, porto no qual a protagonista parece estar ancorada e que é introduzido na narrativa por meio de uma prolepse: "a casa, o colégio e Artur eram os mesmos de sempre" (p. 15).

Nesse cotidiano em tudo igual, o tempo tem suas "horas mortas" acordadas pelo canto do galo que lhe oferece um instante de invulnerabilidade. É impossivel não relacionar essa passagem com o poema de João Cabral no que se refere à força do canto conjunto. A protagonista sente algo diferente ao ouvir o canto do galo, próximo a um estado de alerta que lhe revela sua importância no mundo, o que prova a força da palavra como fator de integração entre os homens.

Para Zumthor (1997, p. 55-56), o ser social "precisa da voz de seus contadores, independente das situações concretas que vive (...) a sociedade precisa de todas as vozes portadoras de mensagens arrancadas à erosão do utilitário: do canto quanto da narrativa". Portanto, o canto do galo, aqui, representa a presença viva da voz, mais viva até do que as vozes utilitárias das personagens que a cercam. Esse canto não precisa passar pelo fio do telefone, porque perfura o círculo ininterrupto do tempo e existe enquanto pura poesia: "aí percebemos essa vontade às vezes cega mas radical, essa energia vital presente nos 
começos de nossa espécie e que luta em nós para roubar nossas palavras à fugacidade do tempo que as devora” (ZUMTHOR, 2005, p. $57)$.

Em contraposição ao despertar, é no meio da noite que Joana convive com a "hora pior de todas" (p. 18) na qual sente a impassibilidade tomá-la: as "imagens passadas que voltavam, ou aquelas que se projetavam no futuro" (p. 18) eram sempre as mesmas. Mesmo durante o dia, o tempo da protagonista é longo e ela deseja a todo custo gastá-lo: "em que iria gastar aquele dia tão longo, com tanto tempo livre para pensar" (p. 24). Felizmente Jô, como é referida ao longo do texto, é paciente como seu homônimo Jó bíblico, não apenas no que diz respeito à longa espera pela vida propriamente (pelo amor, pela mudança) como também nos pequenos atos do dia-a-dia:

O resto do dia passava-o Jô a dar lições particulares nos quatro cantos da cidade ou então, em casa, à espera de um telefonema ou de uma visita sempre possiveis, gastando o tempo, e ingloriamente, a andar de um lado para o outro (p. 17).

Custavam a calçar, era preciso ajudar os dedos a serem vestidos pelos dedos, devagar, pacientemente. Ela entregou-se a isso com paciência, com atenção, como se toda a sua vida dependesse da maneira como aquelas luvas ficavam calcadas" (p. 89).

Figura importante para a compreensão dessa narrativa à deriva é o comandante, vizinho de Jô e dono do galo. Temporalmente emblemático, a ele estão relacionados os termos demodée, relógio, ônibus Cinco, além de prementes, que tem significado de urgência, mas que também significa aquilo que comprime ou pressiona. O comandante é um "oficial de marinha em terra" (p. 19) e representa o estado íntimo e atual de Jô, bem como sua frustração por um esperado futuro que não se concretizou: Jô não se lançou ao mar quando pôde (e a Mário, amor de adolescente), ficando em terra (com Artur, seu indiferente namorado). Joana é, portanto, a duplicidade contida no próprio nome: Jô que se dá a ver e $a n a^{2}$, fatídica repetição que se encontra submersa,

2 Elemento que indica retorno, recuperação, repetição em palavras como analepse, 
à espreita das horas, como se observa no parágrafo final da novela: "O resto, o mais importante, estava ainda bem fundo, escondido ou esquecido, perdido talvez, lá onde nenhum peixe-imagem deslizava." (p. 101).

Sendo assim, no terreno arenoso dessa narrativa fluida, as analepses aparecem a todo o momento: quando olha o retrato com dezessete anos, quando fala do crochet da infância, com suas linhas emaranhadas tão dificeis de desembaraçar quanto são os seus dias. Esse ir-e-vir torna dificil estabelecer um ponto fixo no tempo-espaço a não ser quando, num desses deslizes, ao falar sobre o Inverno e o tempo cíclico que a "fazia episodicamente outra" (p. 23), Jô desenha uma circunferência e revela ao leitor sua idade. Percebe-se, nesse momento, todo o desencanto de uma mulher que, embora não faça isso com clareza, reflete sobre o ser e o não ser jovem: "A circunferência ia-se, porém, desenhando, e voltava a fechar-se. Estava de novo à porta do Inverno. E agora, desta vez, tinha trinta e oito anos, o que não ajudava nada" (p. 24).

Entre as personagens que convivem com a protagonista, Artur é "aquele-olhar-que-fora-azul" (p. 37) e diferente de Jô seus dias são cheios: "tenho um dia terrivel à minha frente, muitíssimo que fazer" (p. 28). Com ele, a protagonista mais imagina coisas do que vive propriamente e, na verdade, não são íntimos, pois ele é duro como a pedra de seu nome. O tempo passado juntos é impalpável para a protagonista: "havia dez minutos (ou dez horas?), perguntara-lhe se queria a janela aberta" (p. 38) o que lhe sugere a não-existência de si mesma: "não tenho passado nem futuro e às vezes recuso-me a ter presente" (p. 38). Apesar disso, Joana deseja um filho, mas não pode têlo, já que Artur tem uma filha curiosamente com dezessete anos, idade de Jô no estimado retrato. Como se vê, a questão temporal é sempre uma barreira entre eles, mesmo quando, frente a frente, tomam o café: "E o Times abriu-se entre ambos" (p. 71). 
Mário é o mar que Joana deixou para trás: "És tu não és? Meu Deus, de onde surgiste?" (p. 48). O retorno é conduzido pelo telefone que faz a "ligação" entre passado e presente: "com o desligar do telefone coincidiu o súbito regresso à vida da professora de História" (p. 49). Mário retorna e mostra-lhe outras paisagens: a vista, a casa, o rio; diz ainda que está de aluguel porque de passagem, afinal não é fixo à terra como Artur. Mário condensa o tempo efêmero do já que já foi e, com ele, toma whisky para "abrirem comportas a rios sem pontes nem barcas, a rios fronteiriços para não serem atravessados" (p. 55).

Nesses momentos com Mário, Jô narra como quem lê um livro (p. 56), retoma a história, resume os acontecimentos no tempo das poucas linhas até Mário lhe perguntar: "Em que estás a pensar?". "Medito", ela responde metalinguisticamente ao leitor, ditando-se toda terra: "seu sentimento tornara-se árido" (p. 57), "mas a que havemos de nos apegar nesta terra senão às coisas terrenas?" (p. 60); enquanto em digressão apresenta-nos um Mário água:

A sua instabilidade era, porém, só física, só seu corpo rebelava-se contra as pessoas quietas e a paisagem imóvel. Estava aqui, estava além. Ninguém compreendia senão ela como ele estava sempre no mesmo lugar" (p. 62).

Mário é aquele que, diferente de Jô, regressou outro, purificado, lavado, "desinfectado" (p. 65) que, única e estranhamente, a faz transbordar: "a enchia toda, transbordava num vago sorriso" (p. 67). Portanto, é o discurso de Mário que a preenche tornando-a apta ao devir, mesmo que passageiro.

Nas prolepses, Jô relembra os sobrenomes dos dois homens que a dividem: Mário Sena (duas vezes água) e Artur Fraga (rocha/ penhasco). Imagens importantes na narrativa, essa oposição representa o ir-e-vir indeciso da protagonista - entre o mar e a margem - que já não se sente fixa em lugar algum.

Nas evocações de vinte anos atrás, conhecemos os acontecimentos que levaram à separação do casal. Agora, "Mário estava 
longe, noutra margem, para além de muito mar e muita bruma e dias e noites de viagem, tão diluído e imprestável, afogado no além-horizonte, que a maior parte das vezes ela não se dava conscientemente conta da sua presença-ausente” (p. 79). Sendo passado, portanto, Mário apenas importa enquanto possibilidade de se pensar o presente como se revela no momento em que Joana é questionada por Mário se estava a pensar nele: "Pensava em ti claro. E em mim." (p. 80).

Cansada, por que "A noite às vezes era grande. E compacta" (p. 89), Joana busca alívio imaginando terminar o relacionamento com Artur. Mas isso não significa que ela ficará com Mário que, também, precisa partir, já que será obrigado a se casar. Jô recebe essa notícia pelo telefone:

Tenho que ir. Recebi um telegrama urgente. Uma complicação Jô. Uma complicação dos diabos. (...) Creio que dessa vez é que me caso. (...) As circunstâncias... (...) Não pense que isso é para mim um drama. Ela é bonita, tem dezoito anos e tenho de casar com ela. Tem de ser, paciência. Não é um drama. (93-95)

Rompe-se o contato, a ligação está cortada: "Mário desligou-o e ela ficou quieta, sem pensar e, com o telefone na mão" (p. 96). Nota-se, portanto, que o destino de Joana é ser só mesmo quando acompanhada.

A aparência de imutabilidade criada na narrativa é eliminada com a transformação quase imperceptível da personagem. Como uma onda que, a cada vai-e-vem, traz mais do seu fundo e leva mais terra consigo, Joana chega ao (re)conhecimento de si mesma. Com Paula ao telefone, Joana confessa sua porção terra cercada de águas por todos os lados: "Sou uma ilha" ela diz "Sim, uma ilha pequena, sem arquipélago, e à volta o oceano desconhecido e um nevoeiro tão denso que não deixava ver os barcos, se os havia. Mas era natural que os houvesse. Há sempre barcos em volta das ilhas" (p. 98). Vê-se, com isso, que o movimento temporal da memória inserido no interior da personagem levou-a ao desenvolvimento da autoconsciência e, principalmente, ao 
reconhecimento de sua condição individual: "Todos o somos, não és original. (...) Mas eu sou aquela ilha” (p. 99, grifos meus).

O fim da narrativa representa um retorno ao início, materializando a circularidade do tempo indiciada no texto e a imagem cronotópica do fio telefônico ligando realidades aparentemente diferentes, mas que são a mesma. O dia se repetirá: “Amanhã, pensou, tenho aulas, duas explicações e um encontro, à noite, com Artur. Enfim, será outro dia embaraçado” (p. 99). As repetições recolhidas ao longo da novela desenham projetos não-concretizáveis e suas lembranças tecem uma "manta de retalhos" (p. 100) compondo a imagem desse ser para sempre fragmentado: Joana, duplo dividido, que tenta fundir sua água - o discurso do tempo que flui e retorna como ondas de memória - à sua terra - a palavra dura e fixa sobre o papel.

\section{O tempo em roda na Ciranda de pedra, de Lygia Fagundes Telles}

Em Ciranda de pedra, embora haja uma cronologia mais acentuada devido à duração do tempo do relato dividido entre a infância e adolescência da protagonista, o presente também se funde ao passado das lembranças próximas ou distantes. Entretanto, convive com esses dois tempos um outro que corre ao lado deles e cujas linhas fronteiriças são bastante tênues: o tempo da fantasia.

Tratamos por tempo da fantasia um tempo analógico feito de solidão, no qual Virgínia se põe a pensar em palavras, imagens, a brincar com insetos, a criar histórias imaginárias; tempo esse que parece descolado da vida das demais personagens:

Podia escrever sobre um homem do campo voltando para casa, enxada no ombro, contente porque sabe que à sua espera estão a mulher e os filhinhos. Na realidade o homem devia de ser esfarrapado e sujo, cercado de crianças barrigudas e piolhentas, mais encardidas do que um tatu. (p. 22) 
Extremamente criativa, Virginia, protagonista de uma narrativa centrada na dissolução familiar, dá aos fatos presentes e passados uma coloração especial, por vezes transformando-os num tempo virtual, criando, por assim dizer, a ficção dentro da ficção. Vê-se aí o movimento temporal da ciranda, da dança de roda que funde e confunde tempos: presente, passado e as respectivas recriações no universo da fantasia.

Nesta narrativa, o fator temporal indissoluvelmente ligado ao espaço também se indicia já no primeiro parágrafo: "Virgínia subiu precipitadamente a escada e trancou-se no quarto”. Aqui, a escada que leva ao quarto (isolamento) tem conotação importante já que sugere o espaço que liga o mundo presente da protagonista ao mundo das ideias - memórias passadas ou criadas por ela.

A circularidade do tempo também é evidenciada na imagem do disco de músicas familiares: 'Os discos que punha para tocar eram sempre os mesmos e tinham um som um pouco gasto como se estivessem esgotados. Mas ele os repetia dez, vinte vezes sem parar. Da cama Virgínia habituara-se àquela música remota e contudo nítida" (p. 48). Ao ouvir a música, Virgínia se deixa povoar de histórias desconexas, contadas por um amigo ambíguo (Daniel? Beethoven? Laura? Ela mesma?) que nunca as termina, voltando incessantemente sobre o mesmo início: "Sabe Virgínia, eu vou contar, era uma vez..."; "Sabe, Virginia, mas eu estava contando" (Idem).

Virginia também é uma personagem dividida e oscilante entre tempos e espaços: infância e adolescência, casa da mãe e casa do pai, dentro e fora do círculo de personagens. Quando finalmente consegue entrar no círculo, Virginia descobre que tudo ao seu redor eram apenas aparências idealizadas por ela mesma: "A estranha ciranda. Eram solidários e no entanto se traiam. Eram amigos e contudo se detestavam" (p. 119), "Os semideuses eram apenas cinco criaturas dolorosamente humanas" (p. 146).

A solidão de Virginia, potencializada pela personalidade introspectiva e os acontecimentos traumáticos (morte da mãe, suicídio 
do pai), colabora para a lentidão dessa narrativa de nuances melancólicas. Os momentos de alegria são aqueles passados junto à ciranda de pedra: “Tem um caramanchão cheio de plantas e, perto do caramanchão, uma fonte no meio de uma roda de cinco anõezinhos de pedra" (p. 20).

Imagem de alto valor cronotópico, a ciranda de pedra representa a dança paralítica do tempo composta pelas personagens antagônicas de Virgínia. Essas personagens são suas irmãs e amigos: "Agora a ciranda de anões mergulhava na escuridão. Ali estavam os cinco de mãos dadas: Conrado, Otávia, Bruna, Afonso, e Letícia" (p. 91), os quais mantêm o círculo fechado impossibilitando sua entrada no grupo, até mesmo Conrado por quem é apaixonada.

Junto à ciranda, Virgínia parece tomada de um "estado poético". Valéry (1999) faz uma interessante analogia entre a dança e a poesia (que se contrapõe ao andar e a prosa) que merece ser lembrada para a leitura de Ciranda de pedra. Para o teórico, tanto a dança quanto a poesia têm o fim em si mesmas e se recriam a cada movimento, o que não ocorre com o andar (e a prosa) cujos passos desaparecem assim que o fim é alcançado. Sendo assim, a dança nunca estaca, ela baila e rodopia sobre si mesma possibilitando contínuas reflexões, como atesta o próprio Valéry (1996, p. 46): “a contemplação da dançarina me faz conceber muitas coisas e muitas relações entre as coisas, que, no momento, constituem meu próprio pensamento, e pensam, de algum modo (...) encontro em mim clarezas".

Entretanto, mais do que a ideia de movimento, Lygia Fagundes Telles conseguiu ampliar essa questão na fusão das imagens cirandapedra sintetizando o movimento do tempo preso na irreversibilidade cíclica da memória. O tempo petrificado de um lado mostra a imutabilidade e irreversibilidade dos fatos; de outro, a resistência e solidez das personagens, que não permitem sua entrada no círculo, e, da própria Virgínia em meio à futilidade que a cerca: 
Aproximou-se dos anõezinhos que dançavam numa roda tão natural e tão viva, que pareciam ter sido petrificados em plena ciranda. No centro, o filete débil da fonte a deslizar por entre as pedras. "quero entrar na roda também" - exclamou ela apertando as mãos entrelaçadas dos anões mais próximos. Desapontou-se com a resistência dos dedos de pedra. Não posso entrar? Não posso? (p. 60)

A força fluida, ininterrupta e paciente da água irá desgastar a rigidez da pedra até que os anões reagirão à protagonista. Esta, já amadurecida, passará a ocupar o centro da roda. Entretanto, engana-se quem pensa que a profecia da infância se cumpriu: "Um dia você também se vestirá como uma princesa e brincará de roda com os anõezinhos" (p. 21). Virginia já não é a princesinha intacta como sugere seu nome, mas, sim, uma mulher que, entre rodopios, transformou-se: "Virginia sorria ainda num relaxamento doce. Sentia um gozo obscuro em ir passando de mão em mão" (p. 115).

Vê-se que o fator temporal trouxe importantes transformações: o ir-e-vir da dança do tempo provocou o deslocamento no espaço, trocando os lugares de "discurso" da ciranda. Os anões, antes estáticos, passam a reagir sensivelmente à palavra provocadora do "outro" Virginia - até então o elemento diferente:

Os cinco - pensou Virgínia encaminhando-se para a roda de pedra. Ali estavam os cinco de mãos dadas, cercando obstinados a fonte quase extinta. Achou-os mais reais, mais humanos, em meio da nevoa da manhã que lhes emprestava uma atmosfera de sonho. Em cada um deles como que havia um segredo, um mistério... "que sabe você de nós?" - Otávia perguntara. Virgínia acariciou a carapuça de uma das cabeças: "Nada" (pág. 145)

Virgínia já não tem o mesmo tamanho, cresceu e se abre ao questionamento da realidade dos fatos, das pessoas e, principalmente, das impressões registradas na infância: "Deteve o olhar na ciranda de anões - anões ou duendes?” (p. 98). As esculturas de pedra guardariam a representação dos seus amigos, inabaláveis e solidificados em sua 
vida, ou seriam apenas seres fantasiosos criados por ela mesma para fazer travessuras em sua mente?

O fim da narrativa apresenta a quebra da ciranda e da sua dança circular: "Retirando a mão da água, mergulhou-a na relva. Não, não, tudo aquilo era já passado, chegara a hora de dizer-lhe adeus. O fluxo da vida, que corria como aquele rio, era tão belo, tão forte!" (p. 146). E Virginia parte a um destino desconhecido, deixando para trás as lembranças: “O rio já ficara para trás” (p. 182). Sua viagem, agora, é para dentro de si mesma, de onde na verdade nunca saiu, com a diferença de que seu tempo agora é o do devir.

Como se vê, Virgínia é, na verdade, a grande dançarina desta narrativa. Proibida de dançar, aprendeu sozinha sua própria dança. Convidada, finalmente, a entrar na roda, desmembrou-a e saiu rodopiando sua auto-suficiência. Como a dançarina Athiktê, de Valéry (1996), Virginia condensa as duas visões a respeito da dança: a de Fedro, metáfora do Amor; e a de Erixímico, "puro exercício intransitivo do corpo".

\section{Considerações finais}

O estudo procurou demonstrar que nessas narrativas o fator temporal é o fio condutor não apenas dos eventos, mas da transformação - em maior ou menor grau das personagens. Além disso, sugere-se que a predominância da temporalidade cíclica ou da linear na construção das narrativas é determinante no caráter e na abertura das personagens à mudança.

Nas narrativas analisadas, a princípio, acredita-se que Joana está submetida à ação de um tempo linear marcado pela paisagem que se estende à sua frente, mas o fio telefônico liga duas pontas de uma mesma história e Mário retorna trazendo com suas águas elementos memoriais. Com Virginia ocorre o mesmo: aparentemente submetida à ação de um tempo petrificado, marcado pela ciranda de pedra, acredita- 
se que ela não será capaz de se transformar, mas o disco de músicas gira continuamente reapresentando as canções e provocando-a a entrar na roda.

Verifica-se, assim, que em ambas narrativas a voz é o elemento que instaura a alteridade, resgatando a memória e rompendo com a linearidade do tempo ao imbuir-lhe de movimento e, consequentemente, circularidade. Para Zumthor (2000, p. 98-99, grifos meus) a voz "repousa no silêncio do corpo": parte dele, mas depois a ele retorna; mesmo a voz dirigida "exige de mim uma atenção que se torna meu lugar, pelo tempo dessa escuta". Essa fusão espácio-temporal saturada de movimento obriga as personagens a se reavaliarem, transformandose e abrindo-se ao devir.

O tempo, ao voltar-se sobre si mesmo, constrói e reconstrói a memória até ela se tornar palavra viva e atuante: em Paisagem sem barcos há o deslizamento dos olhos pelas paisagens temporais, como ondas que correm do mar para a terra, e vice-versa, intercambiando-os; em Ciranda de pedra, o movimento temporal da ciranda, da dança em roda funde e confunde o presente e o passado, reais e virtuais, possibilitando, ao final, novas aberturas.

Apesar das imagens analisadas sugerirem primeiramente permanência e imutabilidade, o futuro das protagonistas parece adquirir novos contornos. A imutabilidade é amenizada em Paisagem sem barcos com a transformação de Jô que chega ao reconhecimento de si mesma enquanto ilha. Mesmo que o autoconhecimento não seja garantia de um futuro rico em possibilidades, pois ao final a protagonista se prepara para um dia igual aos seus dias, agora ela possui consciência de si mesma. Virgínia também acaba por se autoconhecer e a descoberta de si é acompanhada de um projeto de futuro ainda que mal delineado. O lançar-se ao novo (mesmo que esse novo seja o velho revisitado), ao possivel, carrega de devir o tempo das personagens apontando para o seu inacabamento. 


\section{Referências bibliográficas}

BAKHTIN, Mikhail. Estética da criação verbal. 3.ed. São Paulo: Martins Fontes, 2000.

Questões de literatura e estética (A teoria do romance).

4.ed. São Paulo: Editora Unesp, 1998.

CARVALHO, Maria Judite de. Paisagem sem barcos. Lisboa: Editora Arcádia, 1963.

TELlES, Lygia Fagundes. Ciranda de pedra. São Paulo: Abril Cultural, 1982.

VALÉRY, Paul. Variedades. São Paulo: Iluminuras, 1999.

A alma e a dança e outros diálogos. Rio de Janeiro:

Imago, 1996.

ZUMTHOR, Paul. Introdução à poesia oral. São Paulo: Hucitec, 1997. - Performance, recepção e leitura. São Paulo: EDUC, 2000.

Escritura e nomadismo. Cotia: Ateliê, 2005. 